\title{
Study on Loan Pricing Model of Commercial Banks Based on Artificial Neural Network
}

\author{
Ming Zhang1, Xinghua Liu², Yi Liư \\ ${ }^{1}$ Jiangxi University of Finance and Economics, Nanchang, China \\ ${ }^{2}$ School of Finance, Jiangxi University of Finance and Economics, Nanchang, China \\ ${ }^{3}$ Jiangxi College of Foreign Studies, Nanchang, China \\ Email: towmal@126.com, lxh7572@126.com
}

How to cite this paper: Zhang, M., Liu, X.H. and Liu, Y. (2019) Study on Loan Pricing Model of Commercial Banks Based on Artificial Neural Network. Journal of Mathematical Finance, 9, 667-674. https://doi.org/10.4236/jmf.2019.94033

Received: September 16, 2019

Accepted: October 22, 2019

Published: October 25, 2019

Copyright () 2019 by author(s) and Scientific Research Publishing Inc. This work is licensed under the Creative Commons Attribution International License (CC BY 4.0).

http://creativecommons.org/licenses/by/4.0/

cc) (i) Open Access

\begin{abstract}
In recent years, commercial banks and other financial institutions have been carrying out unprecedented reforms on the marketization of interest rates, and the floating space of loan interest rates has been constantly expanding. Therefore, loan pricing has become the most critical link of Chinese commercial banks. It is urgent to construct a scientific and objective loan pricing model so as to keep pace with the competition rhythm of commercial banks in developed countries and make the allocation of financial resources in China more optimized and better serve the economic development of China in the new stage. First of all, this paper analyzes the existing loan pricing model of Chinese commercial banks, deeply recognizes the impact of human subjectivity on loan pricing, and then determines that the core index of loan pricing, namely risk rating, should be evaluated by the objective back propagation algorithm, namely BP algorithm. On the basis of these theories and practices, this paper discusses the new loan pricing model of Chinese commercial banks, that is, the loan pricing based on the risk rating classification of $\mathrm{BP}$ algorithm, and conducts an empirical analysis with the sample customer data. Finally, it gives relevant recommendations from the macro-external factors and its own internal system on improving the loan pricing to commercial banks.
\end{abstract}

\section{Keywords}

Commercial Bank, Loan Pricing Model, Artificial Neural Network

\section{Loan Pricing Model of China's Commercial Banks}

According to the market competition investigation report of China's commercial banks, the problems reflected in the report are summarized and analyzed. 
Therefore, under the background of the current market reform and development, the formation of interest rate has begun to be dominated by the market [1]. As far as the present situation is concerned, there are still many deficiencies in the commercial banks. The most obvious one is that they have not yet constructed a complete, systematic and powerful pricing model, the interest rate pricing has not yet achieved a great breakthrough, and they still have not been able to get rid of the restriction of the central bank to establish the benchmark interest rate, and are not open and free enough. In addition, due to the market awareness has not yet been fully formed, the role of cost and risk has not yet been clearly understood, and the market strategy has not yet formed a rich experience system. These factors can not be the way to determine the market pricing of modern banks [2]. At the same time, they cannot achieve the goal of sustainable development of Chinese commercial banks. Therefore, it is very important for the sustainable development of China's commercial banks to make full use of the development strategy and explore the characteristic loan pricing model in line with the implementation of China's commercial banks. This paper introduces the four pricing modes of loan pricing in China's commercial banks as follows:

Mode 1: A hierarchical pricing model in which interest rates are determined by a single factor. For this kind of pricing model, it only needs one factor to price the interest rate of the loan without considering other factors.

Mode 2: The hierarchical pricing model of interest rate price is determined by many factors. It is characterized by the classification of customer types as the center of gravity, the ultimate customer is divided into stock customers and non-stock customers, the choice of loan methods, loan duration, policy loans and non-policy loans and other types, and then from the above situation to choose two or more influencing factors to determine the interest rate [3]. Compared with Mode 1, there are many determinants of interest rate. Therefore, when pricing, the supply and use of funds can reach a more equitable state because of comprehensive consideration.

Mode 3: A pricing model in which the base rate is regarded as the basis of the price. The characteristic of this pricing model is that each commercial bank reasonably determines the floating ratio of interest rate according to the interest rate basis of the central bank, and the commercial bank often reasonably formulates the interest rate price according to its own operation situation and strategic objectives, and then forms a competitive relationship with other banks.

Mode 4: The pricing model is determined by the risk rating as a condition. It is an important content for commercial banks to consider according to the customer's credit rating, so as to determine the loan pricing according to the customer's credit rating. In order to become the most advanced loan pricing model of commercial banks, the most important thing is to make a reasonable assessment of the risk level, which requires the risk assessors to abandon their subjective factors and use scientific and objective methods to complete the process of risk assessment [4]. 


\section{New Exploration on Loan Pricing Model of Chinese Commercial Banks}

\subsection{Credit Risk Rating by Artificial Intelligence Models}

The rapid development of science and technology has brought about the rapid progress of new artificial intelligence technology. This technology is becoming more and more mature, and it has been widely used in all walks of life. For the banking system, credit risk can also be simulated and tested by artificial intelligence [5]. Therefore, it is a promising method to use artificial intelligence technology to evaluate credit risk by a new method.

In a loan contract, the role of credit risk is self-evident, it is able to price the loan. After discussion and analysis, we can see that the most suitable evaluation model for China is the early warning rating of artificial neural network.

The most remarkable characteristic of BP network is that it contains hidden layer. As shown in Figure 1, it is a neural network model with $\mathrm{R}$ inputs and one hidden layer.

The learning function of BP network is realized by the following methods: In order to realize the fastest speed correction, the most important aspect is to correct according to the negative gradient direction of the error function. In simple terms, the output error of the network needs to be transmitted back to the input layer through the hidden layer after a certain calculation, so as to realize the correction of the weight value.

A three-layer BP network with $\mathrm{m}$ learning samples is presented. The input node is $x_{i}$, the hidden layer node is $x_{j}^{\prime}$, the output node is $y_{n}$, the desired output is $d_{n}$, the weight vector of the hidden layer is $w_{j}$, the weight vector of the output layer is $w_{k}^{\prime}$, the threshold of the hidden layer is $\theta$, the threshold of the output layer is $\theta^{\prime}$, and $f$ is the activation function.

After mathematically reasoning, the modified value of the weight is obtained as follows:

$$
\Delta w_{j}=\eta \sum_{m=1}^{M} \sum\left(d_{n}^{(m)}-y_{n}^{(m)}\right) f^{\prime}\left(\sum_{j} w_{j}^{\prime} x_{j}^{\prime}-\theta^{\prime}\right) w_{j}^{\prime} f^{\prime}\left(\sum_{i} w_{i} x_{i}-\theta\right) x_{i}
$$

Accordingly, the corrected value of the threshold is:

$$
\Delta \theta_{j}=-\eta \sum_{m=1}^{M} \sum\left(d_{n}^{(m)}-y_{n}^{(m)}\right) f^{\prime}\left(\sum_{j} w_{j}^{\prime} x_{j}^{\prime}-\theta^{\prime}\right) w_{j}^{\prime} f^{\prime}\left(\sum_{i} w_{i} x_{i}-\theta\right)
$$

$\eta$ is the learning rate.

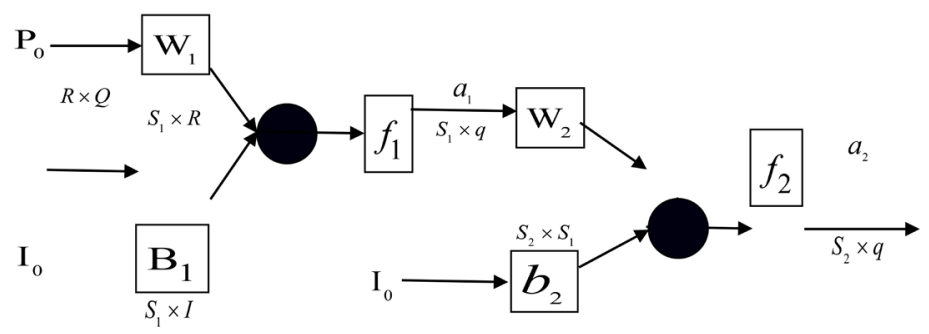

Figure 1. BP Network structure with an implicit layer. 


\subsection{Basic Calculation Model of Loan Pricing}

The basic calculation formula of the benchmark interest rate plus point method is:

$$
\text { Loan Interest Rate }=(1+\text { Floating Rate }) \times \text { Loan Benchmark Interest Rate }
$$

Among them, a series of loan interest rates and floating rates, which are made according to the market interest rate level, are an interest rate policy made by banks according to the purpose of loans, and have the function of controlling the flow direction of funds in the industry. From this, we can get the formula for calculating the loan interest rate of the bank:

Loan Interest Rate $=$ Base Interest Rate $\times\left(1+\sum\right.$ Weight Index $\times$ Floating Ratio $)(4)$

\subsection{Determination of Key Indicators and Their Weights}

Indicators affecting loan interest rates:

Risk index is a very important index in loan interest rate. There are four main methods to evaluate the risk of loan interest rate. The first is to take the credit rating of the customer as the main index of evaluation. The second approach is to look at the customer's balance sheet. The third approach is to look at the profitability of customer loan projects. The fourth method is to evaluate the customer's repayment efficiency and the excellent amount of repayment, as well as the idea of repayment.

Cost-benefit index is to examine the object of three main categories. The first is the amount of revenue generated by adding the total loan interest rate to the estimated cost level; Second, an estimate of the net loan of funds that can be delivered to the customer can be made on the basis of the information gathered; The third step is to assess and calculate the tax returns before the loan [6].

Shareholder index refers to the need to examine the status of equity participation of loan customers.

\subsection{Determination of Floating Rates for Indicators}

1) Customer credit rating ratio. Customers' credit rating is usually divided into two categories, the first category is enterprise customers, and the second category is small loans customers. In the enterprise credit rating, credit rating is generally divided into four grades, namely A, B, C, D grades, in which the highest credit rating is $\mathrm{A}$, the lowest is $\mathrm{D}$ [7]. The credit rating of small loan customers is generally divided into Grade 1 customers and Grade 0 customers. Grade 1 customers refer to customers with higher credit standing, and Grade 0 customers refer to non-credit customers. The credit ratings of both corporate and rural microfinance clients are inversely proportional to the floating rate [8].

2) Loan guarantee method ratio. The guarantee of principal and interest may be provided by the borrower or by a third party.

3) Prospect ratio of the investment project. This ratio is divided into two main categories. One is enterprise investment projects, the other is small loans for farmers. 
4) Single loan ratio. When a bank has a large number of small loans, because the bank uses the same process for each loan, the management cost of unit funds will increase, the extra cost should be included in the cost of interest rate, which is reflected in the interest rate price, that is, floating rate loans will also show an upward trend [9].

5) Customer deposit-loan ratio. The customer's deposit ratio has a direct impact on the customer's credit rating and loan ratio. Therefore, before the loan, we need to make a detailed investigation and understanding of the customer's deposit ratio, and analyze the customer's comprehensive contribution, in which the greater the comprehensive contribution, the smaller the loan ratio.

6) Customer equity ratio. There are many factors that determine the loan interest rate, such as the central bank's policy, the commercial bank's own policy, the nature of the customer's use of funds, customer credit level and so on, for the preferred stock shareholders with good credit.

7) Government policy. The government often interferes with the interest rates on loans by decree. The most obvious example is that in order to support the development of agriculture, the government will give certain preferential interest rates in agriculture-related loans, and eligible customers can enjoy lower interest rates [10].

The calculation of loan interest rate can be based on the index and the floating ratio of the index. The specific formula is:

Floating Proportion of Interest Rates $=\sum($ Floating Ratio $\times$ Weight $) \times 100 \%$

In addition, we also need to take into account that some specific loans and preferential loan interest rates will be calculated differently, so we should pay attention to many factors when calculating the ratio [11].

\subsection{Empirical Analysis and Results}

According to Model 5, and the ratio of indicators and fluctuations, this paper selects the annual data of 30 commercial banks from 2007 to 2017 including large state-owned commercial banks, national joint-stock commercial banks and listed city commercial banks. Sample bank data are obtained from the Bankscope database and annual reports disclosed on the official websites of the banks [12]. The data of monetary policy factors and other related variables come from Wind database, website of National Bureau of Statistics and processing calculation.

The data obtained through the excitation function is substituted into the MATLAB program, and the simulation training diagram is obtained, as shown in Figure 2:

After training, the training result is obtained. After inputting the data, the output result is:

(0.0052, 0.0024, 0.0034, 0.9857). (0.0012, 0.0058, 0.9924, 0.0012) $\rightarrow(0,0,1,0)$, $(0.0052,0.0024,0.0034,0.9857) .(0.0012,0.0058,0.9924,0.0012) \rightarrow(0,0,1,0)$, then we rate the risk to this customer as Grade C. 


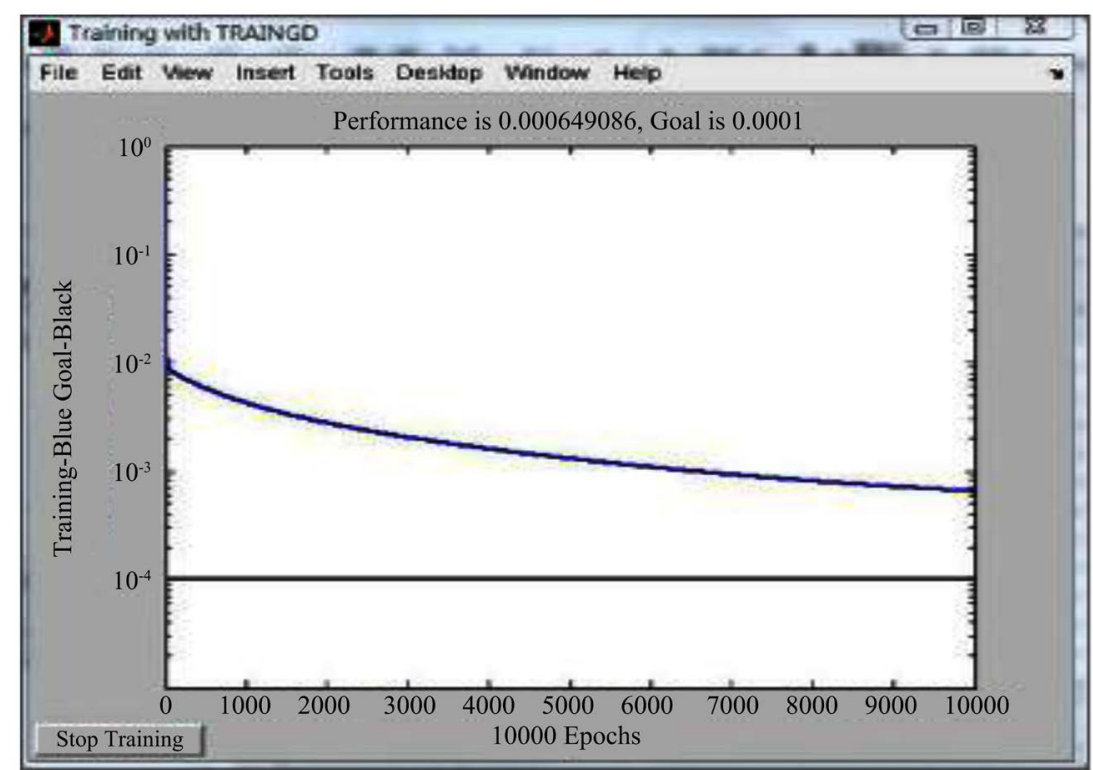

Figure 2. Simulation training diagram.

\section{Conclusion and Enlightenment}

\subsection{Conclusion}

The commercial bank credit risk rating based on artificial intelligence BP algorithm proposed in this paper can effectively according to the interest rate marketization, stand out in the domestic and foreign commercial bank competitive market, and can objectively price the interest rate of loan customers. The findings include:

a) According to the artificial neural network algorithm, the commercial bank carries on the credit risk rating to the customer according to its loan customer's corresponding condition, thus objectively gives the specific loan price to the customer. This adapts to the interest rate marketization tendency which the Chinese commercial bank faces at present.

b) Pricing the loan by artificial neural network can avoid the operational risk of commercial banks. As is known to all, the credit personnel of commercial banks has a lot of human subjective factors in the process of lending to enterprises from pre-loan investigation to on-site visit, which are not independent variables in the model of this paper and can be eliminated well.

c) The size of commercial banks, the level of capital adequacy and China's monetary policy also have an impact on loan pricing. The larger the assets of commercial banks, the higher the capital adequacy level, the lower the loan pricing level for their customers.

\subsection{Policy implications}

a) Diversified reform objectives

The liberalization of interest rates has become an irresistible trend, however, under such circumstances, China has not been developing very well, mainly be- 
cause basically all commercial banks are diversified, the indicators of performance reform and development of commercial banks on the one hand, require the tendency of funds to serve the overall goal of government development, on the other hand, the purpose of the employees' thirst for their positions and salaries in commercial banks can be summed up as follows: the commercial banks should have their own accurate positioning; the business of policy-oriented finance should be mainly related to the national economy and people's livelihood, supplemented by profits; and the current policy-oriented financial institutions are constantly occupying the market share of other financial institutions at a lower cost.

b) Positioning sustainable development

China's commercial banks began to experience a large-scale flourishing environment in 2015. The major commercial banks, including city commercial banks, have blossomed everywhere and established traditional outlets everywhere, which tries to capture the customer base in all regions. Theoretically, the advantages of introducing competition outweigh the disadvantages for the development of financial markets. Mainly in the introduction of competition can better solve some of the problems in the financial market, including the decentralized and smaller economy cannot give better credit services.

\section{Conflicts of Interest}

The authors declare no conflicts of interest regarding the publication of this paper.

\section{References}

[1] Faweett, T. (2006) An Introduction to Roc Analysis. Pattern Recognition Letter, 27, 861-874. https://doi.org/10.1016/j.patrec.2005.10.010

[2] Bikker, J.A., Shaffer, S. and Spierdijk, L. (2012) Assessing Competition with the Panzar-Rosse Model: The Role of Scale, Costs, and Equilibrium. Review of Economics and Statistics, 94, 1025-1044. https://doi.org/10.1162/REST a 00210

[3] DeYoung, R., Gron, A. and Torna, G. (2015) Risk Overhang and Loan Portfolio Decisions: Small Business Loan Supply Before and During the Financial Crisis. Journal of Finance, 70, 2451-2488. https://doi.org/10.1111/jofi.12356

[4] Liu, L.Y., Yu, J.J., Yang, J.Q. and Zhu, X.N. (2017) Is Competition a Double-edged Sword for the Adjustment of Bank Credit Structure?-Microcosmic Evidence of Interest Rate Marketization in China. Economic Research, 52, 131-145.

[5] Zhu, J.G., Li, T.S. and You, K.C. (2017) Real Estate Price Fluctuation and Loan Loss Provision of Commercial Banks: An Empirical Study Based on Chinese Urban Commercial Banks. Financial Research, No. 9, 83-98.

[6] Zheng, X.Y., Zhao, N. and Chen, H. (2016) Interest Rate Corridor, Policy Interest Rate Transmission and Commercial Bank Loan Marketization Pricing-A Comparative Study Based on Chinese and American Practices. Financial Research, No. 7, 92-100.

[7] Zhou, C.X. and Mao, Y (2018). A Study on the Impact of Loan Concentration on Asset Quality in Urban Commercial Banks. Business Economics and Management, No. 9, 86-96. 
[8] Song, W. (2015) Establishment and Empirical Study of Risk Early Warning Model of Shadow Banking in China. Business Research, No. 12, 46-50.

[9] Hu, H.Q., Zhang, L. and Zhang, D.H. (2012) Credit Risk Assessment of Small and Medium-Sized Enterprises from the Perspective of Supply Chain Finance-A Comparative Study Based on SVM and BP Neural Network. Management Review, 24, 70-80.

[10] Chen, Q.G., Fei, W.T. and Chen, L.F. (2010) A Neural Network Approach to Operational Risk Management in Commercial Banks. Productivity Research, No. 6, 73-76.

[11] Yang, Q.H. (2016) Mechanism Analysis of the Impact of Banking Structure on Industrial Structure Upgrading-From the Perspective of Technological Progress and Financial Constraint Reduction. Shanghai Finance, No. 9, 13-19.

[12] Cai, Y.P. and Sun, X. (2016) Performance Evaluation System of Listed Commercial Banks Based on BP Neural Network. Systems Engineering, 34, 24-30. 